\title{
Reed Nevus (Pigmented Spindle Cell Nevus) in an 11-Month-Old Japanese Infant
}

\author{
Miyuki Fujita, Naoki Oiso*, Akira Kawada \\ Department of Dermatology, Faculty of Medicine, Kinki University, Osaka, Japan. \\ Email: "naoiso@med.kindai.ac.jp \\ Received September $6^{\text {th }}, 2012$; revised October $8^{\text {th }}, 2012$; accepted October $17^{\text {th }}, 2012$
}

\begin{abstract}
Reed nevus (pigmented spindle cell nevus) is a nevus with the histopathological features of abundant melanin, monomorphic spindle-epithelioid melanocytes, spindle cell nests confined within the epidermis and papillary dermis, and occasional upward interepidermal progression of melanocytes. Here, we reported an unusual case of Reed nevus in an 11-month-old Japanese male infant. Infantile Reed nevus should be included as a differential diagnosis for nevus pigmentosus in infancy.
\end{abstract}

Keywords: Reed Nevus; Pigmented Spindle Cell Nevus; Spitz Nevus; Malignant Melanoma; Infant

\section{Introduction}

Reed nevus (pigmented spindle cell nevus) is an expansive, intensely and uniformly pigmented plaque or papule which generally occurs on the legs in twenties and thirties [1]. Some authors use the term to describe a distinct entity that differs from Spitz nevus, and others consider Reed nevus as a pigmented variant of Spitz nevus [1-3]. Caucasians is more frequently affected than Asian populations. Here, we describe a Japanese infantile case of Reed nevus.

\section{Case Report}

An 11-month-old Japanese male infant visited us in April 2012 with an asymptomatic black macule on the right lower leg. At the age of three months, the parents noticed a pigmented dot, which gradually developed in size and darkened in color. A physical examination revealed an asymptomatic, well-demarcated blackish macule, $4 \mathrm{~mm}$ in size, on the right lower leg (Figure 1(a)). Dermoscopy showed a homogeneous black-brown pigmentation at the center and a starburst pattern with multiple pigmented streaks at the periphery (Figure 1(b)). The blackish macule was excised.

Hematoxylin and eosin staining showed symmetric and deeply pigmented proliferation of spindle-shaped melanocytes with band-like dermal macrophages in the junctional lesion and the papillary dermis (Figure 1(c)). The specimen showed the junctional and dermal nests of spindle melanocytes, lack of sharp demarcation between

${ }^{*}$ Corresponding author. the nests of melanocytes and the epidermis, upward interepidermal progression of melanocytes, and the abundant melanin deposits throughout the epidermis including in the corneal layer (Figure 1(d)). Mitoses and Kamino bodies were not detected.

\section{Discussion}

Reed nevi show black plaques or papules with three main dermoscopic patterns; starburst, globular and multicomponent (atypical and melanoma-like). The histopathologic features of the most commonly used to distinguish Reed nevus from Spitz nevus include: 1) abundant melanin; 2) monomorphic spindle-epithelioid melanocytes; 3) spindle cell nests confined within the epidermis and papillary dermis; and 4) occasional upward interepidermal progression of melanocytes [3]. The present case was consistent with dermoscopic and histopathologic criteria. Thus, we diagnosed the eruption as Reed nevus rather than Spitz nevus. We believe that our case was extremely uncommon, because no Reed nevi were found in less than one-year-old infants in two studies of 120 cases by Barnhill et al. [4] and 95 cases by Sau et al. [5].

The pathogenesis of Reed nevus is still unknown. Malignant melanomas are associated with multiple chromosomal abnormalities and mutations in protooncogenes and tumor suppressor genes. Using a fluorescence in situ hybridization (FISH) assay with a four-color probe for RREB1, MYB, CCND1, CEP6, Martin et al. confirmed that Spitz nevi from 19 of 51 (37\%) patients had changes in the investigated loci [6]. In 1999, Bastian et al. con- 


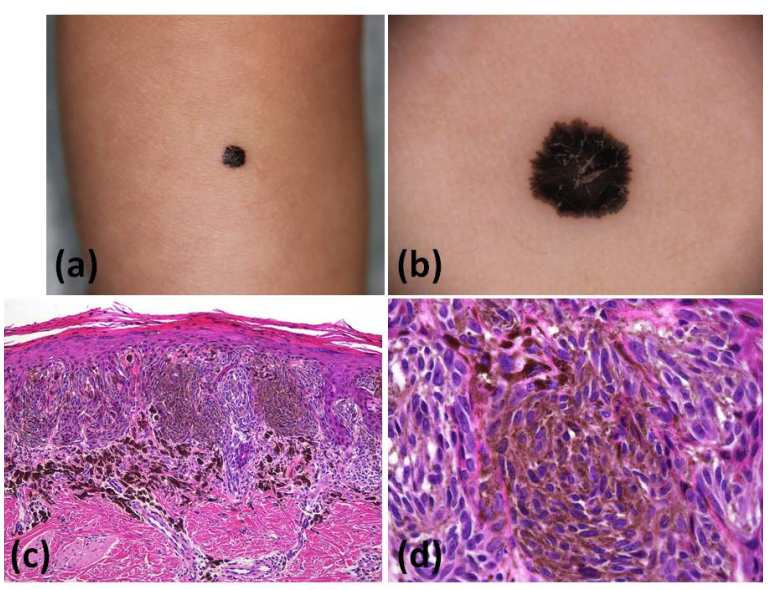

Figure 1. (a) Clinical appearance of an asymptomatic, welldemarcated blackish macule on the right lower leg. (b) Dermoscopic appearance of a homogeneous black-brown pigmentation at the center and a starburst pattern with multiple pigmented streaks at the periphery. (c) and (d) Histopathologic figures showed symmetric and deeply pigmented proliferation of spindle-shaped melanocytes with band-like dermal macrophages in the junctional lesion and the papillary dermis (hematoxylin and eosin stain, original magnification: $c \times 100$ and $d \times 400)$.

cluded that the majority of Spitz nevi have a normal chromosomal complement at the level of comparative genomic hybridization (CGH) resolution, but some may contain additional copy numbers [7]. As current CGH analysis can more precisely detect alternations of genomic DNA copy numbers [8], a modern evaluation of the genomic DNA copy numbers in both Reed nevi and Spitz nevi would provide more accurate results for increased or decreased copy number alternations as well as reveal similarities and/or dissimilarities in chromosomal alternations. Furthermore, we could elucidate the pathogenetic resemblances and/or divergences with comparison the results of current CGH analysis in adult Reed nevi with the results in infantile and children Reed nevi.

In summary, we describe an uncommon case of Reed nevus in an 11-month-old Japanese male infant. Reed nevus should be included as a differential diagnosis for melanocytic nevi in infants, even though it is rare especially in the Asian population.

\section{REFERENCES}

[1] K. K. Boneti, J. Piñeiro-Maceira, F. B. Pereira and C. B. Barcaui, "Reed Nevus (Pigmented Spindle-Cell Nevus): A Report of Three Cases with Distinct Dermoscopic Patterns," Anais Brasileiros de Dermatologia, Vol. 85, No. 4, 2010, pp. 531-536. doi:10.1590/S0365-05962010000400016

[2] G. Ferrara, G. Argenziano, H. P. Soyer, S. Chimenti, A. Di Blasi, G. Pellacani, K. Peris, D. Piccolo, P. Rubegni, S. Seidenari, S. Staibano, I. Zalaudek and G. De Rosa, "The Spectrum of Spitz Nevi: A Clinicopathologic Study of 83 Cases," Archive of Dermatology, Vol. 141, No. 11, 2005, pp. 1381-1387. doi:10.1001/archderm.141.11.1381

[3] S. A. Webber, G. Siller and H. P. Soyer, "Pigmented Spindle Cell Naevus of Reed: A Controversial Diagnostic Entity in Australia," Australian Journal of Dermatology, Vol. 52, No. 11, 2011, pp. 104-108. doi:10.1111/j.1440-0960.2011.00743.x

[4] R. L. Barnhill, M. A. Barnhill, M. Berwick and M. C. Mihm Jr., "The Histologic Spectrum of Pigmented Spindle Cell Nevus: A Review of 120 Cases with Emphasis on Atypical Variants," Human Pathology, Vol. 22, No. 1, 1991, pp. 52-58. doi:10.1016/0046-8177(91)90061-S

[5] P. Sau, J. H. Graham and E. B. Helwig, "Pigmented Spindle Cell Nevus: A Clinicopathologic Analysis of NinetyFive Cases," Journal of American Academy of Dermatology, Vol. 28, No. 4, 1993, pp. 565-571. doi:10.1016/0190-9622(93)70075-5

[6] V. Martin, S. Banfi, A. Bordoni, S. Leoni-Parvex and L. Mazzucchelli, "Presence of Cytogenetic Abnormalities in Spitz Naevi: A Diagnostic Challenge for Fluorescence in Situ Hybridization Analysis," Histopathology, Vol. 60, No. 2, 2012, pp. 336-346. doi:10.1111/i.1365-2559.2011.04087.x

[7] B. C. Bastian, U. Wesselmann, D. Pinkel and P. E. Leboit, "Molecular Cytogenetic Analysis of Spitz Nevi Shows Clear Differences to Melanoma," Journal of Investigative Dermatology, Vol. 113, No. 6, 1999, pp. 1065-1069. doi:10.1046/j.1523-1747.1999.00787.x

[8] N. Oiso, Y. Tatsumi, T. Arao, S. Rai, M. Kimura, S. Nakamura, T. Itoh, K. Nishio, I. Matsumura and A. Kawada, "Loss of Genomic DNA Copy Numbers in the p18, p16, p27 and RB Loci in Blastic Plasmacytoid Dendritic Cell Neoplasm," European Journal of Dermatology, Vol. 22, No. 3, 2012, pp. 393-394. 